\title{
A new opportunity for science in Europe
}

\author{
Françoise Praderie*
}

\begin{abstract}
Closer integration between European research and the needs of society would have a positive effect on the development of Europe while helping to shape the future of its scientific communities. To promote those aims we intend to create 'Euroscience', an open association of all those interested in science and its consequences on society.
\end{abstract}

THE relationship between science and the public can be comfortable (as in the public's continuing fascination with astronomical discoveries) or stressed (see, for example, debates concerning the implications of genetic analysis and modification). The links between rapidly expanding human knowledge and the evolving needs of society are never static, and merit continuous appraisal, as do the activities of the various groups of participants. In turn, such appraisal should lead to feedback that can stimulate and enhance those to whom it is directed.

We believe that, at a European level and within many European countries, there is inadequate opportunity for such feedback. But we also believe that new opportunities can be created. As a result of enhanced consideration and dialogue, new partnerships between society and science can be invented: scientific approaches to society's demands can be more effectively and considerately matched; the partnerships can better adapt to changes in the process of knowledge generation and also respect the intrinsic constraints and uncertainties of basic research; and they can take account of changing conditions in the public perceptions of science. Another anticipated benefit is that scientists can become more aware of society's needs and concerns, and be more ready to invest their expertise in tackling them.

In addition, there is a need for a higher degree of integration between the scientific communities of European countries. Despite efforts to promote a better coordination of European research through common structures (especially for large facilities), national research programmes are still insufficiently interactive, hindering the ability to reconcile expanding knowledge and the interests of those it serves.

We have begun the process of establishing an organization intended to address these problems. Called Euroscience, it has already attracted members from Europe's research community as a result of personal contacts. The purpose of this first public announcement is to invite others to become involved.

In the most general terms, Euroscience is intended to analyse perspectives of science and the future of the scientific

* On behalf of the founding members of Euroscience. workforce in Europe in the light of challenges faced by European countries and their societies. There is a clear analogy with the role in the United States of the American Association for the Advancement of Science.

More specifically, the initial priorities of Euroscience will be to:

- investigate more effective strategies to define and address society's demands in terms of science and technology;

- define ethical guidelines for evaluating and managing science programmes and disseminating their results.

- appraise prospects for the careers and employment of young scientists and the adequacy of current education systems (for instance, postdoctoral training and guidance), in the context of society's changing needs;

- promote closer integration of the scientific workforce throughout Europe at large and thereby preserve a necessary diversity of available skills in research;

- learning from the experience accumulated in some countries, take initiatives that would improve the understanding between scientists and the public of the roles of science and of scientists in our societies;

- address Europe's responsibilities towards other countries developing through science and technology;

- act as an additional channel for the views of scientific communities towards government bodies, including the institutions of the European Union, as well as national agencies and research councils.

To these ends, Euroscience will provide open forums for scientists, teachers and students in all fields of humanities, social and natural sciences, for those interested in developing science and technology, and for anyone interested in these issues. Forums should result in practical proposals to implement Euroscience's objectives, for instance by addressing reports to science agencies, government bodies, parliaments, the media and others.

\section{Complementarity}

Euroscience is not intended to be a learned society, an academy or a trade union, although it plans to work in cooperation with all institutions sharing similar goals, such as European learned socicties, the European Science Foundation and Academia Europaea. It is open to anyone having a vested interest in science, technology and their impact on society: teachers; scientists actively involved in research and education (academic and industrial, young and established, representing all areas of science and engineering including social sciences and the humanities); and partners of science from the media, industry, science management and consumer groups.

\section{Initial activities}

A document "Call to European scientists for the creation of a large, multidisciplinary movement for the promotion of science and technology in Europe" was drafted in April 1996 and circulated by a small group of initiators. It received immediate support from 145 distinguished scientists from 22 countries and all disciplines, hereafter referred to as "founding members". They agreed to help launch Euroscience. They represent a fair balance of disciplines, and are drawn from across the whole of Europe. A list of founding members is available from the e-mail address in the box below.

Most founding members were selected because of their high scientific visibility and broad political views of science, to achieve scientific credibility at this initial stage. That explains why the first call for founding membership was relatively restricted. However, all founding members insist that Euroscience should be open to anyone sharing our concerns.

A meeting of founding and potential members will convene on 15 March 1997 in Strasbourg. It will elect a provisional Board, including a chairperson and vice-presidents, responsible for proposing by-laws, preparing elections and initiating priorities to be discussed on that occasion. Financial resources will be sought on a regular basis through individual fees, and through gifts and donations from institutions in the launch phase.

\section{Contacting Euroscience}

Europeans from all countries of geographical Europe who share these views and would like to join the Euroscience project can obtain additional information by writing to: Françoise Praderie, Observatoire de Paris, 61 Avenue de l'Observatoire, F75014 Paris, France. e-mail: francoise.praderie@obspm.fr 